\title{
Neurogenesis in the Dentate Gyrus of the Adult Rat: Age-Related Decrease of Neuronal Progenitor Proliferation
}

\author{
H. Georg Kuhn, Heather Dickinson-Anson, and Fred H. Gage \\ Laboratory of Genetics, The Salk Institute, La Jolla, California 92037
}

The hippocampus is one of the few areas of the rodent brain that continues to produce neurons postnatally. Neurogenesis reportedly persists in rats up to 11 months of age. Using bromodeoxyuridine (BrdU) labeling, the present study confirms that in the adult rat brain, neuronal progenitor cells divide at the border between the hilus and the granule cell layer (GCL). In adult rats, the progeny of these cells migrate into the GCL and express the neuronal markers NeuN and calbindin- $D_{28 k}$. However, neurogenesis was drastically reduced in aged rats. Six- to 27-month-old Fischer rats were injected intraperitoneally with BrdU to detect newborn cells in vivo and to follow their fate in the dentate gyrus. When killed 4-6 weeks after BrdU labeling, 12- to 27-month-old rats exhibited a significant decline in the density of BrdU-positive cells in the granule cell layer compared with 6-month-old controls. Decreased neurogenesis in aging rats was accompanied by reduced immunoreactivity for poly- sialylated neural cell adhesion molecule, a molecule that is involved in migration and process elongation of developing neurons. When animals were killed immediately (12 hr) after BrdU injection, significantly fewer labeled cells were observed in the GCL and adjacent subgranular zone of aged rats, indicative of a decrease in mitotic activity of neuronal precursor cells. The reduced proliferation was not attributable to a general age-related metabolic impairment, because the density of BrdU-positive cells was not altered in other brain regions with known mitotic activity (e.g., hilus and lateral ventricle wall). The decline in neurogenesis that occurs throughout the lifespan of an animal can thus be related to a decreasing proliferation of granule cell precursors.

Key words: neurogenesis; proliferation; precursor cells; progenitor cells; granule cells; hippocampus; aging
In most regions of the mammalian brain, the production of neurons is largely confined to the prenatal period. However, in the dentate gyrus of several species, including rat, mouse, rabbit, guinea pig, and cat, granule cells are generated postnatally (Altman and Das, 1965; Altman and Das, 1967; Caviness, 1973; Guéneau et al., 1982). In the rat, neurogenesis continues well into adulthood. The newborn granule cells are capable of extending axonal projections along the mossy fiber tract to their natural target area, the hippocampal CA3 region (Stanfield and Trice, 1988), and exhibit all ultrastructural features associated with neurons (Kaplan and Hinds, 1977). Although neurogenesis in the rat hippocampus was found at up to 11 months of age (Kaplan and Bell, 1984), it is still unclear whether neuronal birth continues throughout the lifespan of an animal.

The aging hippocampus undergoes a variety of structural and functional alterations that are strongly regional and cell-specific (Finch, 1993; Barnes, 1994). Degenerative changes include neuronal cell loss in the hilus and CA regions (Landfield et al., 1981; Flood and Coleman, 1988; West et al., 1994), reduced synaptic density (Bondareff and Geinisman, 1976), reduced postlesion sprouting (McWilliams and Lynch, 1984), and decreased glucose utilization (Gage et al., 1984). However, other changes are indicative of a compensatory increase in hippocampal function and include elevated postsynaptic efficacy of granule cell synapses

\footnotetext{
Received Oct. 3, 1995; revised Dec. 22, 1995; accepted Dec. 28, 1995.

This work was supported by grants from the National Institute on Aging. H.G.K was supported by the Deutsche Forschungsgemeinschaft. H.D.A. was supported by National Institutes of Health (5T32 AG00216). We thank Drs. Gerd Kempermann, Theo Palmer, and Heather Raymon for critical review of this manuscript.

Correspondence should be addressed to Fred H. Gagc, The Salk Institute, Laboratory of Genetics, P.O. Box 85800, San Diego, CA 92186-5800.

Copyright (C) 1996 Society for Neuroscience $0270-6474 / 96 / 162027-07 \$ 05.00 / 0$
}

(Barnes and McNaughton, 1980; Barnes et al., 1991), increased average dendritic extent in the dentate gyrus (Flood and Coleman, 1990), and increased NMDA receptor function (Serra et al., 1994). Remarkably, the density of granule cells in the dentate gyrus increases during adulthood (Baycr, 1982; Bayer et al., 1982) and is at least constant during aging (Bondareff and Geinisman, 1976), suggesting that age-related functional decline in the dentate gyrus may not be mediated by a loss of granule cells, but rather by a decline in the birth of new granule cells.

The process of neurogenesis in the adult dentate gyrus can be divided into three distinct phases. First, neural precursor cells that reside at the border between the hilus and the granule cell layer (GCL) undergo cell division. Early markers of this proliferation are incorporation of bromodeoxyuridine (BrdU) or $\left[{ }^{3} \mathrm{H}\right]$ thymidine into the DNA of dividing precursor cells and increased immunoreactivity to the cell cycle regulatory protein RB (the retinoblastoma susceptibility gene product) and to the cell cycledependent kinase cdc2 (Okano et al., 1993). Sccond, newborn cells begin to migrate into the GCL and extend neuronal processes. This step is accompanied by expression of polysialylatedNCAM (PSA-NCAM), the embryonic form of neural cell adhesion molecule (Seki and Arai, 1993). The presence of PSANCAM in the embryonic and adult brain is highly correlated with neuronal precursor migration and differentiation (Chuong and Edelman, 1984; Bonfanti et al., 1992; Ono et al., 1994; Rousselot et al., 1994). In the adult hippocampus, PSA-NCAM is present in cells that reside at the border between hilus and GCL, including newborn granule cells (Seki and Arai, 1993). Third, the cells integrate into the GCL and begin to express the neuronal marker neuron-specific enolase (Cameron et al., 1993).

In the present study, we examined whether neurogenesis is 

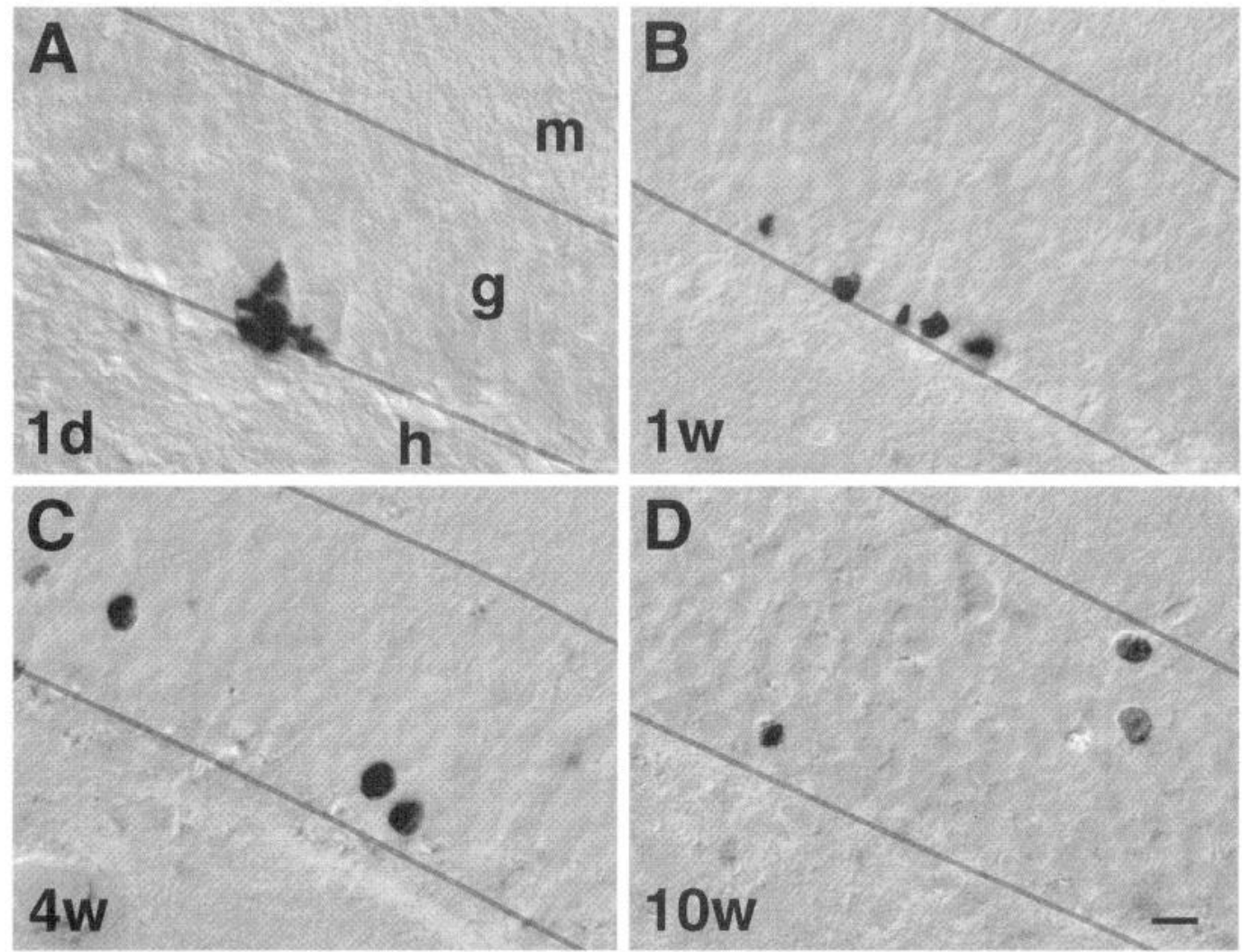

Figure 1. Proliferation and migration of granule cell precursors in the adult rat dentate gyrus. Rats were killed $1 \mathrm{~d}(A), 1$ week $(B), 4$ weeks $(C)$, and 10 weeks $(D)$ after injection with BrdU and stained for BrdU immunohistochemistry. Note the irregular shape of BrdU-positive nuclei at $1 \mathrm{~d}$ and 1 week as opposed to the round nuclear shape at 4 and 10 weeks after BrdU injection. $h$, Hilus; $g$, granule cell layer; $m$, molecular layer. Interference-contrast optics. Scale bar (shown in $D$ ), $10 \mu \mathrm{m}$.

altered in the aging rat hippocampus. We combined BrdU labeling and immunohistochemistry to study the proliferation, migration, and differentiation of granule cell precursors in the dentate gyrus of 6- to 27-month-old rats.

\section{MATERIALS AND METHODS}

BrdU labeling. For migration and double-labeling experiments (Figs. 1 and 2), 3-month-old Fischer 344 rats were injected intraperitoneally four times with $\mathrm{BrdU}(50 \mathrm{mg} / \mathrm{kg})$ over the course of $12 \mathrm{hr}$ and were killed $1 \mathrm{~d}$, 1 week, 4 weeks, and 10 weeks later. For all other experiments, female Fischer 344 rats were injected intraperitoneally six times with BrdU (50 $\mathrm{mg} / \mathrm{kg}$ ) over 3 consecutive days (8:00 A.M. and 6:00 P.M.). For the first aging experiment (Figs. 3-6), 6- and 21-month-old animals were killed either $1 \mathrm{~d}$ ( $n=6$ per group) or 6 weeks ( $n=2$ per group) after the BrdU injections. For the second aging experiment (Fig. 7), 6-, 12-, and 27month-old animals were killed at 4 weeks after the BrdU injections ( $n=5$ per group). After an anesthetic overdose, all animals were transcardially perfused with $4 \%$ paraformaldehyde. Brains were removed, post-fixed in $4 \%$ paraformaldehyde for $24 \mathrm{hr}$, and stored in $30 \%$ sucrose solution. Coronal freezing microtome sections $(40 \mu \mathrm{m})$ were stored in cryoprotectant $(25 \%$ ethylene glycol, $25 \%$ glycerin, $0.05 \mathrm{M}$ phosphate buffer) at $-20^{\circ} \mathrm{C}$ until processing for immunohistochemistry or immunofluorescence.

Antibodies and immunochemicals. The following antibodies and final dilutions were used: mouse (mo) $\alpha$-BrdU, 1:400 (Boehringer Mannheim, Indianapolis, IN); mo $\alpha$-BrdU-FITC, 1:25 (Boehringer Mannheim); mo $\alpha$-PSA-NCAM, 1:2500 (clone MenB kindly provided by Dr. G. Rougon, Marseille, France); mo $\alpha$-calbindin- ${ }_{28 \mathrm{k}}, 1: 2000$ (Sigma, St. Louis, MO); mo $\alpha$-NeuN, 1:50 (clone A60 kindly provided by Dr. R. Mullen, Salt Lake City, UT); biotinylated horse $\alpha$-mouse IgG, 1:160 (Vector Laboratories, Burlingame, CA); avidin-biotin-peroxidase complex, 1:100 (Vectastain Elite, Vector); biotinylated donkey $\alpha$-mouse, 1:80; streptavidin-Texas Red, 1:250 (both from Jackson Immunoresearch, West Grove, PA).

DNA denaturation. For detection of BrdU-labeled nuclei in tissue sections, the following DNA denaturation steps preceded the incubation with anti-BrdU antibody: $2 \mathrm{hr}$ incubation in $50 \%$ formamide $/ 2 \times$ $\mathrm{SSC}(0.3 \mathrm{M} \mathrm{NaCl}, 0.03 \mathrm{M}$ sodium citrate $)$ at $65^{\circ} \mathrm{C}, 5 \mathrm{~min}$ rinse in $2 \times \mathrm{SSC}$, 30 min incubation in $2 \mathrm{~N} \mathrm{HCl}$ at $37^{\circ} \mathrm{C}$, and $10 \mathrm{~min}$ rinse in $0.1 \mathrm{M}$ boric acid, $\mathrm{pH} 8.5$.

Immunohistochemistry. Free-floating sections were treated with $0.6 \%$ $\mathrm{H}_{2} \mathrm{O}_{2}$ in Tris-buffered saline (TBS) $(0.15 \mathrm{M} \mathrm{NaCl}, 0.1 \mathrm{M}$ Tris- $\mathrm{HCl}, \mathrm{pH} 7.5)$ for $30 \mathrm{~min}$ to block endogenous peroxidase. Several rinses in TBS were then followed by incubation in TBS $/ 0.25 \%$ Triton X-100/3\% normal horse serum (TBS-TS) for $30 \mathrm{~min}$ and incubation with primary antibody in TBS-TS overnight at $4^{\circ} \mathrm{C}$. After rinsing in TBS-TS, cells were incubated for $1 \mathrm{hr}$ with biotinylated secondary antibodies. With intermittent rinses in TBS, avidin-biotin-peroxidase complex was applied for $1 \mathrm{hr}$ followed by peroxidase detection for $5 \mathrm{~min}(0.25 \mathrm{mg} / \mathrm{ml}$ diaminobenzidine, $0.01 \%$ $\mathrm{H}_{2} \mathrm{O}_{2}, 0.04 \% \mathrm{NiCl}$ ). For PSA-NCAM immunodetection, the nuclei were counterstained with $1 \%$ methyl green. For double labeling, sections were first stained with an $\alpha$-calbindin- $\mathrm{D}_{28 \mathrm{k}}$ antibody using 4-chloro-1-naphtol (Vector) as a gray peroxidase substrate. After DNA denaturation (see above), $\alpha$-BrdU-antibody was detected using aminoethylcarbazole (Vector) as a red peroxidase substrate.

Immunofluorescence. Sections were treated for DNA denaturation as described above, followed by incubation in TBS-TS for $30 \mathrm{~min}$. NeuN-antibody was applied in TBS-TS for $48 \mathrm{hr}$ at $4^{\circ} \mathrm{C}$ and was detected with a biotin-labeled donkey $\alpha$-mouse IgG and streptavidin-Texas Red, each for $2 \mathrm{hr}$. BrdU was then detected with an $\alpha$-BrdU-antibody coupled to fluorescein (FITC). Fluorescent signals were detected and processed using a confocal scanning laser microscope (Bio-Rad MRC600, Richmond, CA) and Adobe Photoshop (Adobe Systems, Mountain View, CA).

Quantification. From serial coronal sections $(40 \mu \mathrm{m})$ of the lateral ventricle and the dorsal hippocampus, every sixth section was selected from each animal and processed for immunohistochemistry. Sections from the dorsal hippocampus were analyzed for immunopositive cells in the GCL and the hilus. The subgranular zone, defined as a 2-cell body wide zone along the border of the GCL and the hilus, was always 

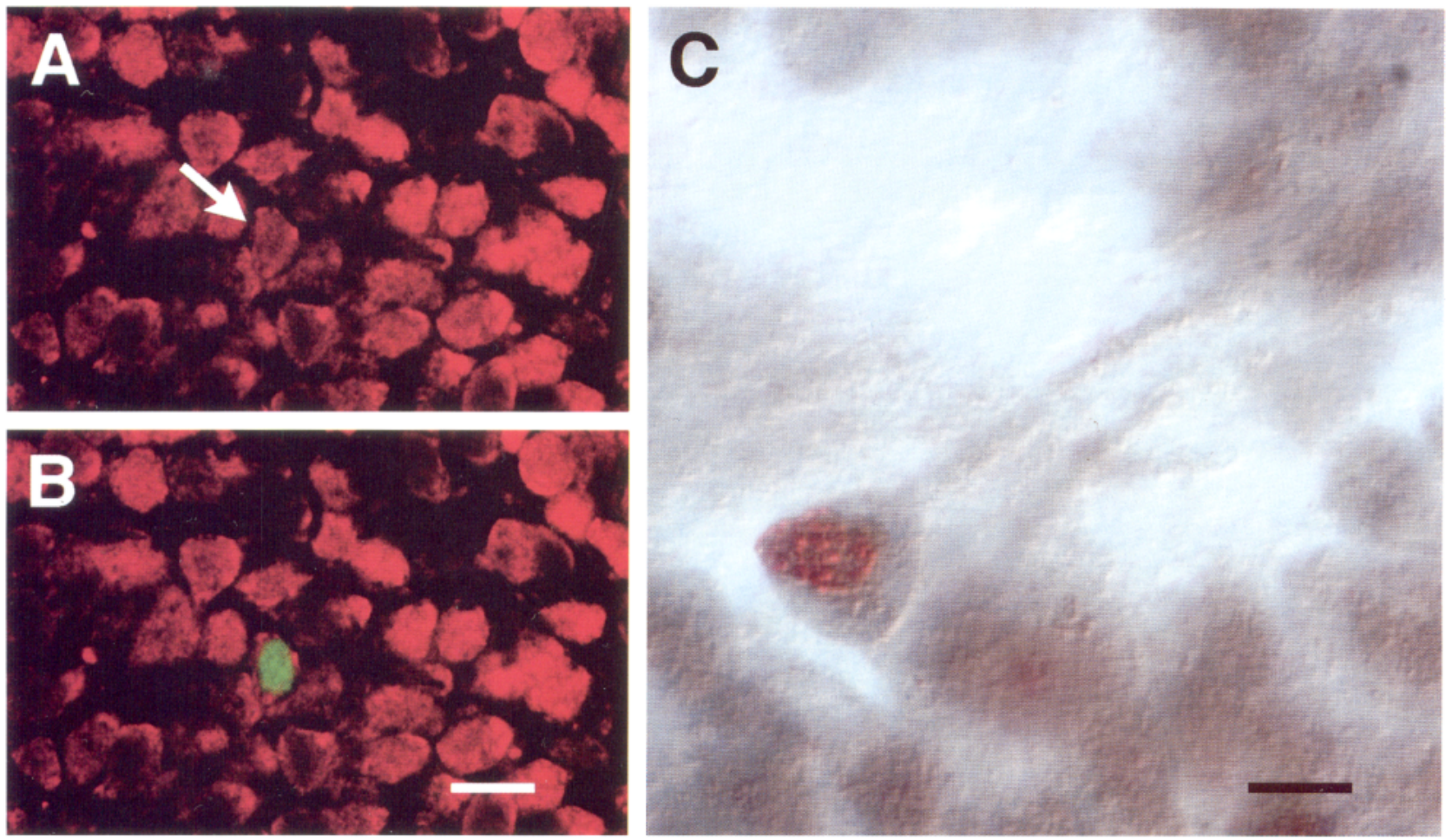

Figure 2. $A, B$, Neuronal phenotype of newborn granule cells in the adult dentate gyrus. Immunofluorescence labeling for BrdU was combined with labeling for NeuN and analyzed with a confocal scanning laser microscope. NeuN-immunoreactive neurons (red) form the granule cell layer of the dentate gyrus. A newborn granule cell is double-labeled for $\mathrm{NeuN}$ and $\mathrm{BrdU}$ (arrow in $A$ and green in $B$ ). $C$, Granule cell-specific labeling of newborn cell in the adult dentate gyrus. Calbindin- $\mathrm{D}_{28 \mathrm{k}}$ and BrdU immunohistochemistry were combined on a section from a 4-month-old rat at 4 weeks after BrdU labeling. A newborn cell is indicated by the BrdU-positive nucleus (red), double-labeled for calbindin (gray), a protein typically expressed in granule cells. Note the calbindin-positive apical process extending from the cell body. Interference-contrast optics. Scale bars: $B, 10 \mu \mathrm{m} ; C, 5 \mu \mathrm{m}$.

combined with the GCL for quantitation. To present the number of immunopositive cells as cells $/ \mathrm{mm}^{2}$, the areas of the GCL and hilus on each section were determined using a semiautomatic image analysis system (Metamorph, Universal Imaging, West Chester, PA). To avoid over- or undersampling of BrdU-positive nuclei because of size differences, we determined the size (area) of BrdU-positive nuclei in the granule cell layer for 6- and 27-month-old rats $(n=119$ and $n=63$, respectively). Because no statistical difference in the nuclear area was found between the age groups $(p>0.18)$, no stereological correction for sampling errors was applied. For quantitation of BrdU-positive cells in the lateral ventricle wall, a fixed area of $0.15 \times 0.15 \mathrm{~mm}$ was selected on each section (see inset in Fig. 6C). All BrdU-positive nuclei in this selected area were counted and calculated as cells $/ \mathrm{mm}^{2}$. Statistical analysis was performed using either Student's $t$ test or ANOVA followed by post hoc comparison using the Fisher least square difference test.

\section{RESULTS}

Neurogenesis in the adult and aged dentate gyrus can be monitored by BrdU incorporation into nuclei of dividing cells. In Figure 1, the rat dentate gyrus is depicted at 3 months of age at different intervals after systemic injection of BrdU. Typically, cells are born in the subgranular zone at the border between the GCL and the hilus region with clusters of irregularly shaped nuclei reaching into the GCL (Fig. $1 A$ ). One week after BrdU injection, the newborn cells align along the border of the GCL (see Fig. 1B). After 4-10 weeks, the labeled cells have migrated into the GCL and can be found throughout the whole layer (Fig. $1 C, D$ ). At this stage, the nuclei are usually large and round, characteristics of mature granule cells. To determine whether the newborn cells express a neuronal phenotype, we combined immunofluorescent labeling for BrdU and the novel neuronal marker NeuN (Mullen et al., 1992) on sections from animals treated with BrdU 4 weeks before they were killed. NeuN stained neuronal cells in the GCL, including newborn cells labeled with BrdU (Fig. $2 A, B$ ). Furthermore, we combined BrdU and calbindin- $\mathrm{D}_{28 \mathrm{k}}$ immunohistochemistry. Calbindin, typically found in dentate gyrus granule cells (Sloviter, 1989), was also expressed by newborn cells in the GCL (Fig. 2C).

To study the effects of aging on neurogenesis in the dentate gyrus, we injected 6- and 21-month-old rats with BrdU for a total of six times over $3 \mathrm{~d}$. Two animals per age group were killed after 6 weeks, a survival interval that gave newborn cells enough time to develop into their differentiated phenotype. Quantitative analysis was performed by calculating the density of BrdU-positive cells in the GCL. As depicted in Figure $3 A$, BrdU-positive nuclei were distributed throughout the GCL of 6-month-old rats. In contrast, in 21-month-old rats, large areas of the GCL were devoid of BrdU-positive nuclei (Fig. 3B). This finding is reflected in the density of BrdU-positive cells in the GCL of 21-month-old rats, which was decreased to $\sim 10 \%$ of the adult level (Fig. $3 C$ ).

Several mechanisms could be responsible for the reduction in dentate gyrus neurogenesis during aging. Neuronal precursor cells could either change their migratory activity, leading to displacement of newborn cells, or alter their mitotic activity, leading to a reduction of the actual number of newborn cells.

Because it has been suggested that PSA-NCAM is involved in the maturation of newborn granule cells (Seki and Arai, 1993), we used PSA-NCAM as a marker for migration and differentiation and compared PSA-NCAM immunoreactivity in the dentate gyrus of 6- and 21-month-old rats. As depicted in Figure 4, PSANCAM-positive cells are located at the base of the granular zone 

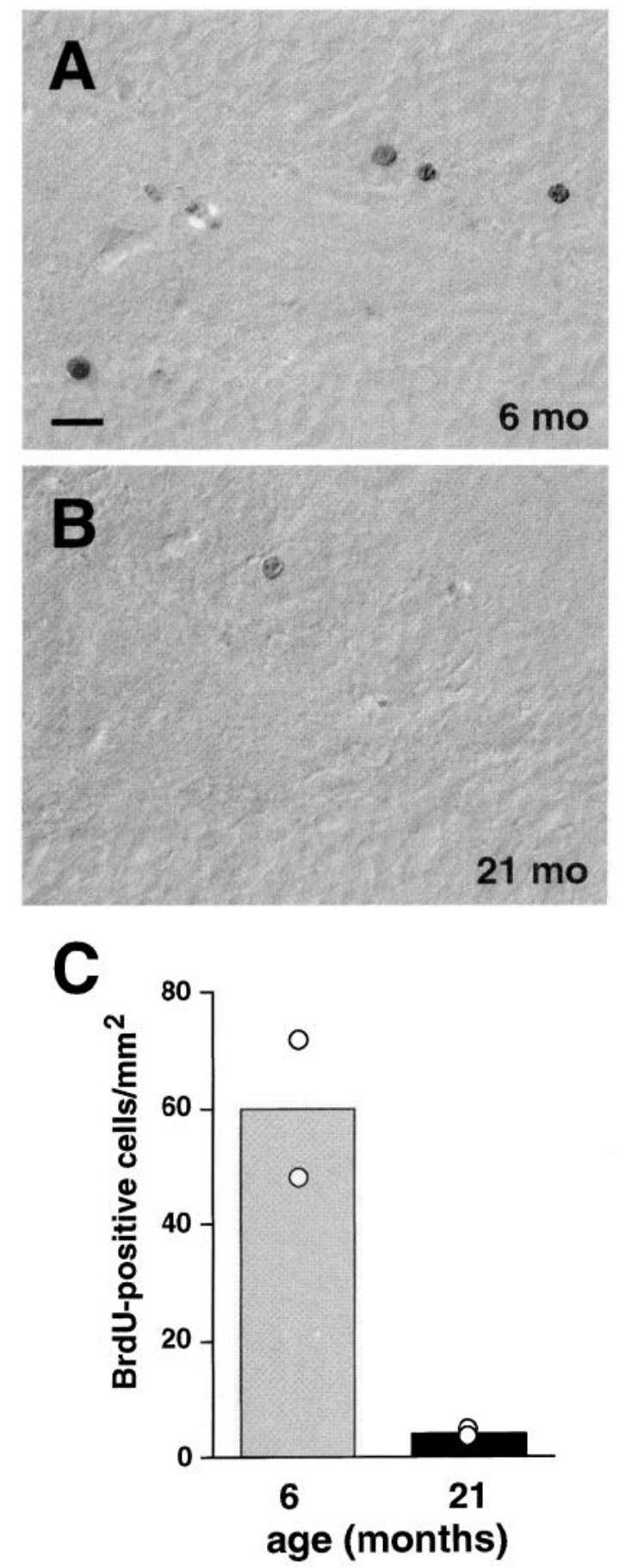

Figure 3. Decreased neurogenesis in aged rats. Newborn cells in the granule cell layer of 6-month-old $(A)$ and 21-month-old $(B)$ rats were labeled with BrdU immunohistochemistry 6 weeks after BrdU injection. Interference-contrast optics. Scale bar (shown in $A$ ), $25 \mu \mathrm{m}$. $C$, Quantification. The dorsal hippocampus of two rats per group was bilaterally analyzed on eight coronal sections per animal. The amount of cell birth is expressed as the number of BrdU-positive cells $/ \mathrm{mm}^{2}$ in the granule cell layer. Individual scores for each animal are depicted as open circles.

and extend processes through the GCL into the molecular layer. In 21-month-old rats, the density of PSA-NCAM-positive cells in the granular zone was significantly reduced to $12 \%$ of the adult level ( $p<0.001$; Fig. 4). Decreased neurogenesis in aged rats is thus accompanied by a compatible decrease in PSA-NCAM expression.
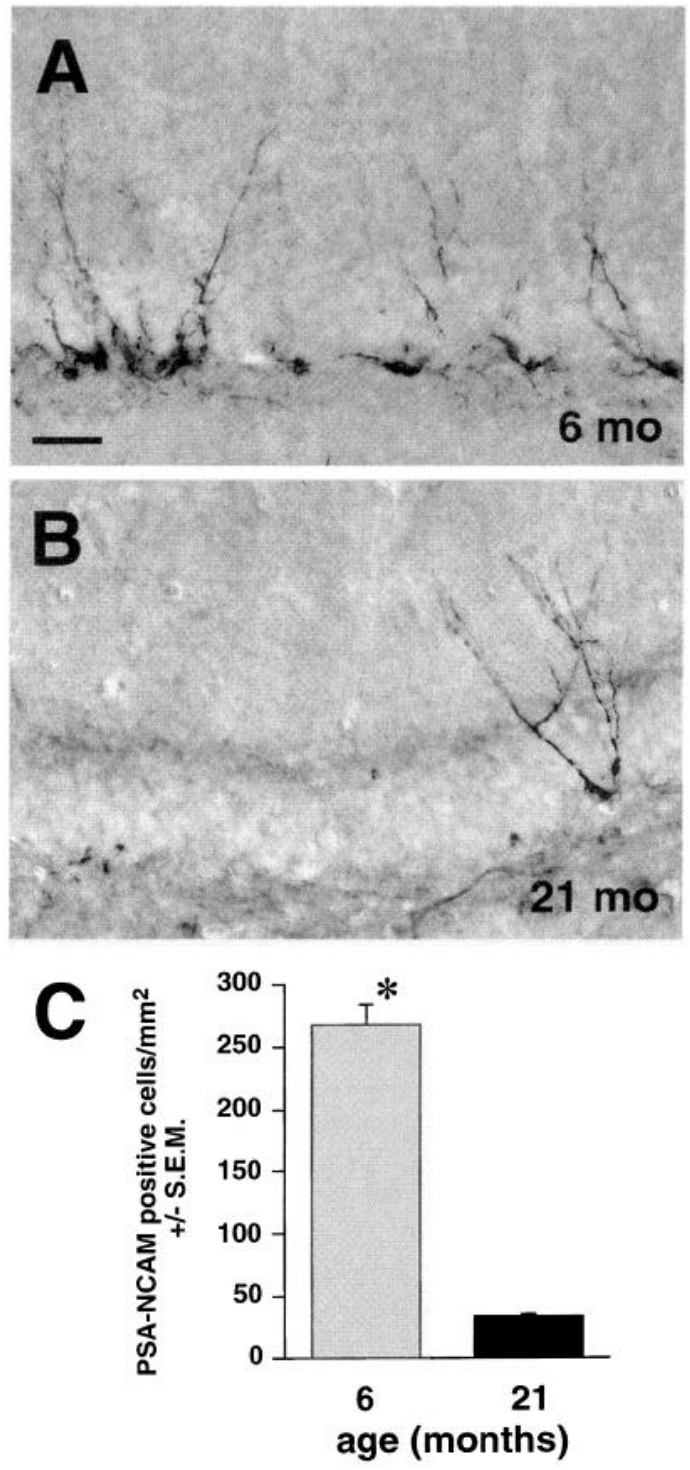

Figure 4. PSA-NCAM expression in adult and aged rats. The granule cell layer of 6-month-old $(A)$ and 21-month-old $(B)$ rats was stained for PSA-NCAM immunohistochemistry. Note the typical position of PSANCAM-positive cell bodies at the border of the granule cell layer and the hilus. Nuclei were stained with methyl green. Interference-contrast optics. Scale bar (shown in $A$ ), $40 \mu \mathrm{m}$. $C$, Quantification. The dorsal hippocampus of six rats per group was bilaterally analyzed on six coronal sections per animal. The amount of PSA-NCAM immunoreactivity is expressed as the number of PSA-NCAM-positive cell bodies $/ \mathrm{mm}^{2}$ in the granule cell layer. Asterisk indicates statistically significant difference between adult and aged animals $(p<0.001$, Student's $t$ test).

To determine whether reduced neurogenesis in the aged dentate gyrus is attributable to decreased proliferative activity of neuronal precursor cells, we analyzed the density of newborn cells immediately after BrdU labeling. Six and 21-month-old animals ( $n$ $=6$ per group) were injected with BrdU for a total of six times over $3 \mathrm{~d}$ and were killed $12 \mathrm{hr}$ after the last injection. In 6-monthold rats, most of the newborn cells were arranged in clusters along the subgranular zone (Fig. $5 A$ ). The same pattern could be observed in 21-month-old rats (Fig. 5B), although the density of BrdU-immunoreactive cells was significantly reduced to $\sim 20 \%$ of the adult level ( $p<0.0001$; Fig. $5 C$ ).

Because the reduced proliferation of neuronal precursor cells 

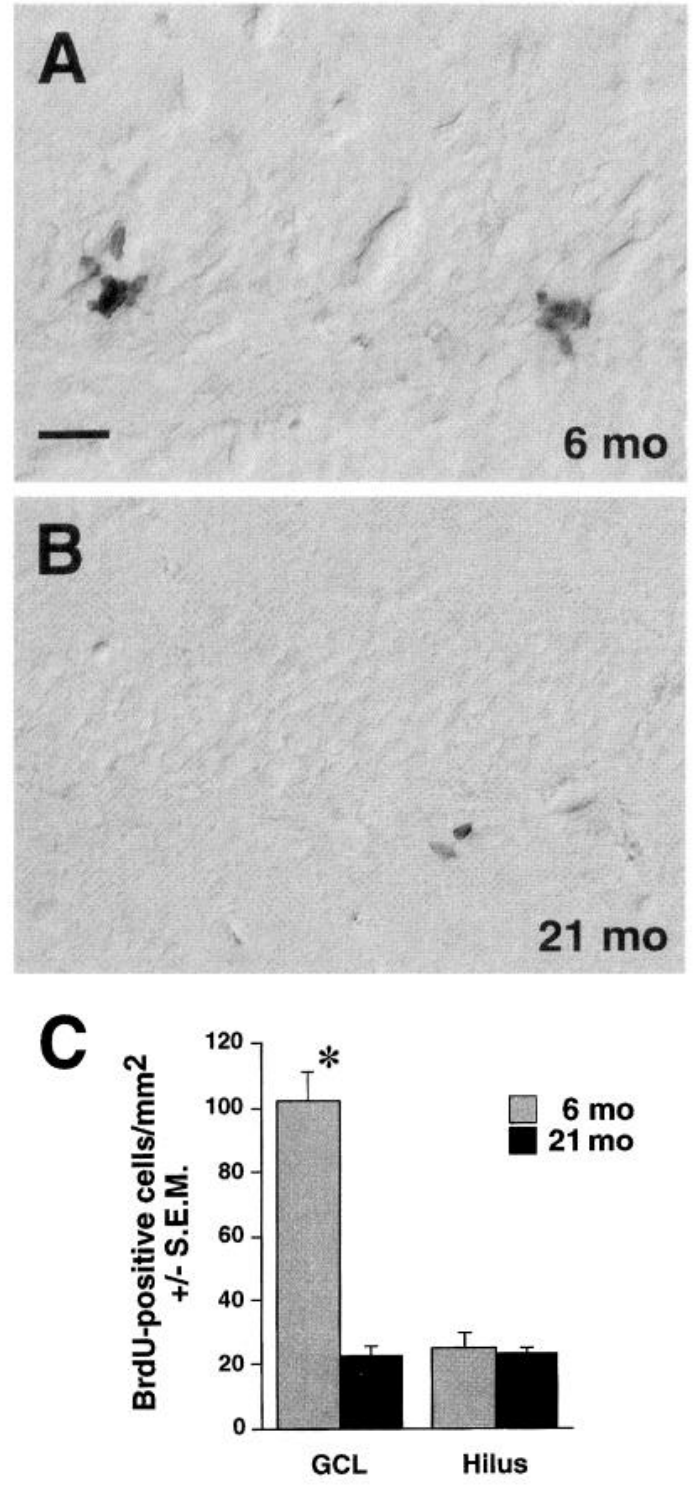

Figure 5. Cell proliferation in the dentate gyrus. Cell division in the granule cell layer of 6-month-old $(A)$ and 21-month-old $(B)$ rats was visualized by BrdU immunohistochemistry $1 \mathrm{~d}$ after BrdU injection. Note the typical clustering of newborn cells at the inner border of the granule cell layer. Interference-contrast optics. Scale bar (shown in $A$ ), $25 \mu \mathrm{m}$. $C$, Quantification. The dorsal hippocampus bilaterally analyzed on eight coronal sections per animal ( $n=6$ /group). The proliferative activity in the dentate gyrus is expressed as the number of BrdU-positive cells $/ \mathrm{mm}^{2}$ in the granule cell layer and the hilus, respectively. Asterisk indicates statistically significant difference between adult and aged animals $(p<0.001$, Student's $t$ test).

could be attributable to a general age-related metabolic impairment, we compared the GCL with two other brain regions of known proliferative activity (Altman, 1963). Neither the hilus region of the hippocampus (Fig. $5 C$ ) nor the subependymal zone of the lateral ventricle (Fig. 6) showed any statistical difference in the density of BrdU-positive cells between 6- and 21-month-old rats (both areas $p>0.5$ ).

To expand the previous observations of attenuated neurogenesis in 21-month-old rats to other time points, we compared the production of granule cells in 6-, 12-, and 27-month-old rats. Animals were killed 4 weeks after BrdU injection and analyzed for newborn cells in the GCL of the dorsal hippocampus (Fig. 7). The density of BrdU-positive cells in the GCL decreased significantly in 12- and 27-month-old rats compared with 6-month-old controls $(p<0.0001)$, whereas no difference was found between the 12 and 27-month-old animals $(p>0.2)$. The production of cells in the GCL undergoes a steady decline during aging with significant reduction observed as early as 12 months of age.

\section{DISCUSSION}

Previous studies have shown that neurogenesis is an ongoing process in the dentate gyrus of adult rodents. The birth of granule cells was reported in rats up to 11 months of age (Kaplan and Bell, 1984) and was assumed to continue throughout the lifespan of an animal. In this report, we analyzed neurogenesis in the rat dentate gyrus using BrdU immunohistochemistry. In adult rats, neuronal progenitor cells divide at the border of the hilus and the GCL. One day after labeling, a large portion of BrdU-positive cells is still arranged in clusters, suggesting that single progenitor cells might give rise to clonal populations of immature granule cells (Figs. $1 A, 5 A$ ). After alignment along the inner border of the GCL and migration into the GCL, the newborn cells exhibit a granule cell-specific phenotype. Here we report for the first time that newborn granule cells from the adult rat express NeuN, a novel marker for postmitotic neurons (Mullen et al., 1988), and calbindin- $\mathrm{D}_{28 \mathrm{k}}$, a calcium-binding protein commonly expressed by mature granule cells (Sloviter, 1989). However, as a major result of this study, we have found that neurogenesis in the dentate gyrus steadily declines during aging. Four to 6 weeks after BrdU injection, the density of BrdU-positive cells in the GCL of aged rats reached only $10-17 \%$ of the adult level (6 months of age). Even 12 -month-old animals showed a significant decrease in neurogenesis compared with 6-month-old controls. Postnatal neurogenesis has its origin at a perinatal stage when neuronal progenitor cells form the germinal matrix of the subgranular zone (Altman and Bayer, 1990). After an initial peak around the second postnatal week, neurogenesis declines during adolescence (Altman and Das, 1965) and, as demonstrated in this study, continues to decline during adulthood and senescence. In this context, aging in the hippocampal granule cell layer is accompanied by a gradual decrease in the birth and differentiation of new granule cells rather than a loss of granule cells.

Several mechanisms can be responsible for the reduction of neurogenesis: (1) the neuronal precursor cells that reside in the subgranular zone may decrease their proliferative activity; (2) an aberrant or inhibited migratory mechanism could displace the newborn cells; and (3) an increasing number of newborn cells could die before differentiating into granule cells. To test the first hypothesis, we determined the density of BrdU-positive cells $1 \mathrm{~d}$ after labeling. We were able to determine the proliferative activity in the dentate gyrus before the migration or death of newborn cells. We found that the number of dividing cells in the GCL and adjacent subgranular zone was significantly diminished in aged rats. Although we cannot rule out other mechanisms such as cell death, reduction of proliferative activity of granule cell precursors seems to be a major contributor to decreased neurogenesis in the aged rat.

Because the aging organism can be subject to generalized changes in metabolic conditions, the observed reduction in precursor cell division could be attributed to a generalized reduction of mitotic activity in the brain. Therefore, we analyzed two other brain regions with known proliferation in the adult rat. Neither the hilus region, with typical glial proliferation (Landfield et al., 1981), nor the lateral ventricle wall, a source of glial and neuronal 

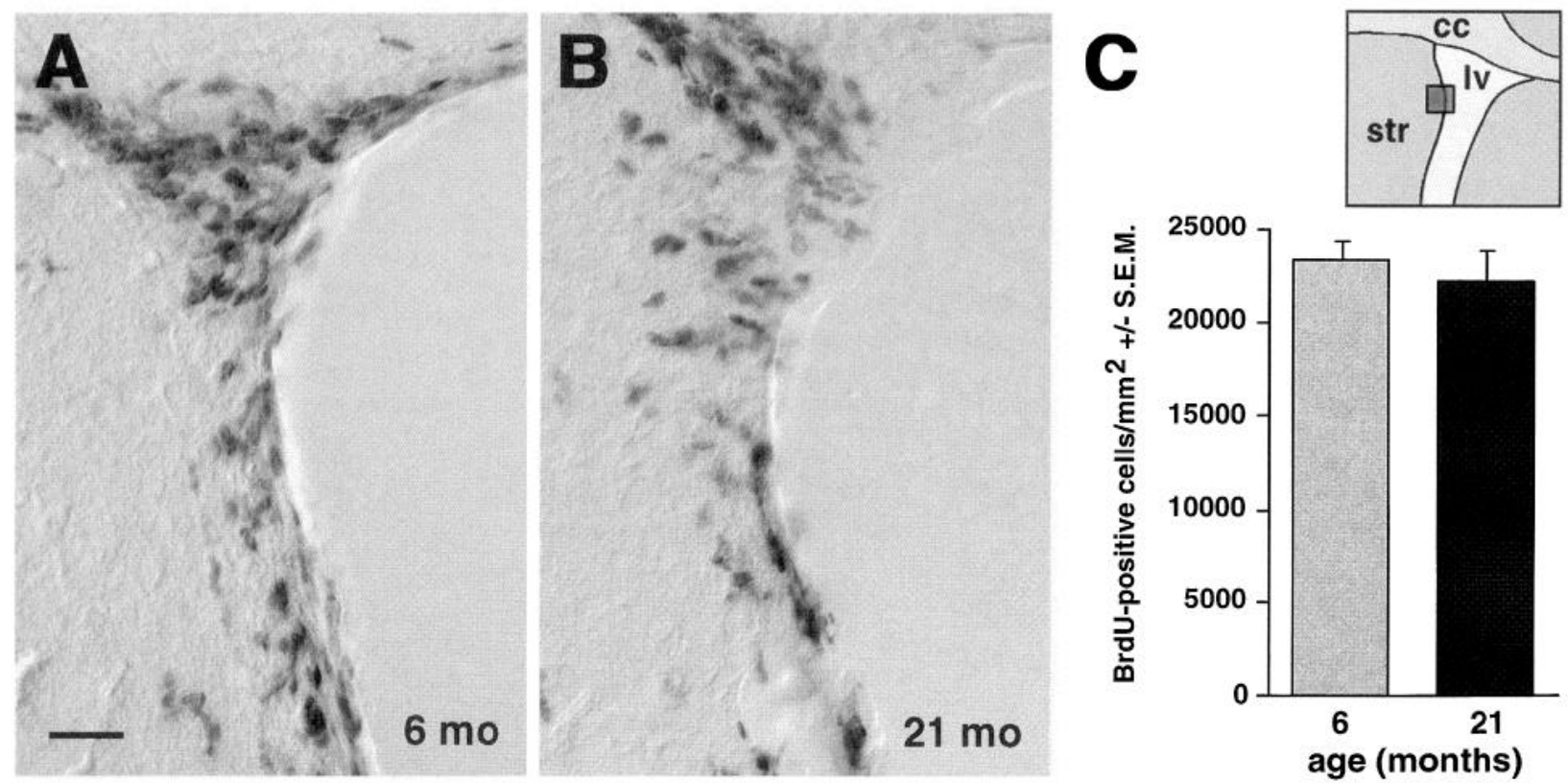

Figure 6. Cell proliferation in the lateral ventricle wall. The subventricular zone of 6-month-old $(A)$ and 21 -month-old $(B)$ rats was analyzed using BrdU immunohistochemistry $1 \mathrm{~d}$ after BrdU injection. Interference-contrast optics. Scale bar (shown in $A$ ), $25 \mu \mathrm{m}$. $C$, For quantitation of BrdU-positive cells, a fixed area of the lateral ventricle wall (shaded square on inset in $C$ ) was analyzed on four coronal sections at the level of the anterior commissure ( $n=$ 6 rats/group). All BrdU-positive nuclei were counted and expressed as the number of BrdU-positive cells $/ \mathrm{mm}^{2}$.

precursors (Lois and Alvarez-Buylla, 1993; Levison et al., 1993), changed its density of BrdU-positive cells during aging. We thus conclude that the age-related attenuation of proliferation is specific to the granule cell precursors of the dentate gyrus.

PSA-NCAM is typically expressed in the subgranular zone by newborn granule cells and neighboring cells, where it is thought to be involved in migration of cells from the subgranular zone into the GCL (Seki and Arai, 1993). In this study, the density of PSA-NCAM in 21-month-old rats showed a highly significant reduction compared with 6-month-old animals. Recently, Regan and Fox (1995) also reported a significant reduction in the density of PSA-NCAM-positive cells when comparing 18-month-old rats

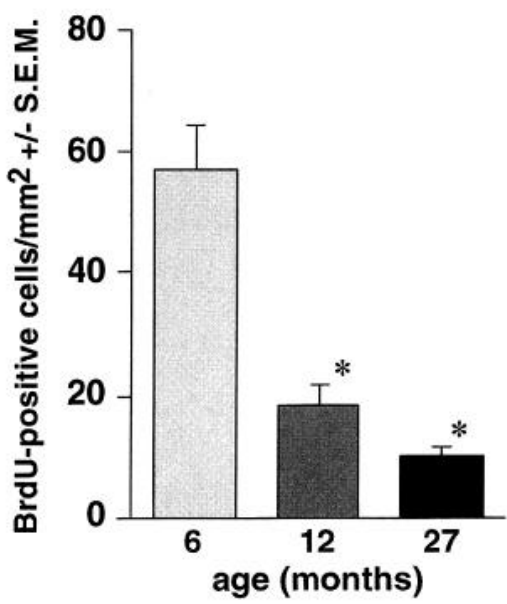

Figure 7. The dorsal hippocampus of 6-, 12-, and 27-month-old rats was bilaterally analyzed for BrdU-positive cells on six coronal sections $(n=5$ rats/group). The amount of cell birth in the granule cell layer is expressed as the number of BrdU-positive cells $/ \mathrm{mm}^{2}$. Asterisks indicate statistically significant differences for 12- and 27-month-old rats compared with 6 -month-old rats $(p<0.0001$, ANOVA and Fisher least square difference test). to 6- and 12-week-old animals. Taking these findings together, we can assume that the presence of PSA-NCAM in the dentate gyrus is continuously declining with age. This parallels the age-related decline in dentate gyrus neurogenesis. Although a functional link between granule cell neurogenesis and PSA-NCAM has not been established yet, it is very intriguing that the large majority of PSA-NCAM-positive cells is located in the basal portion of the GCL, where the maturation of newborn granule cells occurs. Given the association of PSA-NCAM with migrating neurons, it seems likely that PSA-NCAM plays a role in migration of newborn neurons from the subgranular zone into the GCL. Whether PSA-NCAM is produced exclusively by the newborn cells or whether it is also produced by adjacent cells that provide extrinsic guidance cues remains to be determined.

The progressive decline of precursor cell proliferation during aging raises the question of whether the precursor cells become unresponsive to environmental cues or whether the environment does not provide the stimuli for further proliferation. The first hypothesis would imply that the cells either die or lose their appropriate signaling mechanism (e.g., extracellular receptor) for the mitotic stimulus. The second hypothesis would imply that, during aging, the local environment for the precursor cell changes so that the mitotic stimulus is no longer provided. Several factors that regulate neuronal birth in the adult dentate gyrus were recently described. Blockade of adrenal steroids, blockade of excitatory input into the dentate gyrus, and NMDA receptor inactivation all lead to an increased birth of granule cells (Gould et al., 1992; Gould et al., 1994; Cameron et al., 1995). In vitro studies with adult and embryonic hippocampal cultures indicate a strong role for peptide growth factors, such as fibroblast growth factor-2, in the proliferation of neuronal progenitor cells (Ray et al., 1993; Gage et al., 1995; Palmer et al., 1995). The fact that newborn cells could still be detected at low levels in the GCL of senescent rats (21-27 months of age) makes the aging dentate gyrus a valuable model for the study of altered neurogenesis. It 
remains to be determined to what extent the precursor cells in the aged brain are capable of responding to growth factors or other drugs with reentry into the cell cycle and neurogenesis.

Although the biological significance of adult neurogenesis is not known, it occurs specifically in an area involved in memory formation and thus may contribute to the optimal functioning of this region. Future studies need to determine its biological function and whether the decrease in neurogenesis is involved in early stages of age-related memory impairment.

\section{REFERENCES}

Altman J (1963) Autoradiographic investigations of cell proliferation in the brains of rats and cats. Anat Rec 145:573-591.

Altman J, Bayer SA (1990) Migration and distribution of two populations of hippocampal granule cell precursors during the perinatal and postnatal periods. J Comp Neurol 301:365-381.

Altman J, Das GD (1965) Autoradiographic and histological evidence of postnatal hippocampal neurogenesis in rats. J Comp Neurol 124:319-335.

Altman J, Das GD (1967) Postnatal ncurogenesis in the guinea-pig. Nature 214:1098-1101.

Barnes CA (1994) Normal aging: regionally specific changes in hippocampal synaptic transmission. Trends Neurosci 17:13-18.

Barnes CA, McNaughton BL (1980) Physiological compensation for loss of afferent synapses in rat hippocampal granule cells during senescence. J Physiol (Lond) 309:473-485.

Barnes CA, Foster TC, Rao G, McNaughton BL (1991) Specificity of functional changes during normal brain aging. Ann NY Acad Sci 640:80-85.

Bayer SA (1982) Changes in the total number of dentate granule cells in juvenile and adult rats: a correlated volumetric and $\left[{ }^{3} \mathrm{H}\right]$ thymidine autoradiographic study. Exp Brain Res 46:315-323.

Bayer SA, Yackel JW, Puri PS (1982) Neurons in the rat dentate gyrus granular layer substantially increase during juvenile and adult life. Science 216:890-892.

Bondareff W, Geinisman Y (1976) Loss of synapses in the dentate gyrus of the senescent rat. Am J Anat 145:129-136.

Bonfanti L, Olive S, Poulain DA. Theodosis DT (1992) Mapping of the distribution of polysialylated neural cell adhesion molecule throughout the central nervous system of the adult rat: an immunohistochemical study. Neuroscience 49:419-436.

Cameron IIA, Woolley CS, McLwen BS, Gould L (1993) Differentiation of newly born neurons and glia in the dentate gyrus of the adult rat. Neuroscience 56:337-344.

Cameron HA, McEwen BS, Gould E (1995) Regulation of adult neurogenesis by excitatory input and NMDA receptor activation in the dentate gyrus. J Neurosci 15:4687-4692.

Caviness Jr VS (1973) Time of neuron origin in the hippocampus and dentate gyrus of normal and reeler mutant mice: an autoradiographic analysis. J Comp Neurol 151:113-120.

Chuong CM, Edelman GM (1984) Alterations in neural cell adhesion molecules during development of different regions of the nervous system. J Neurosci 4:2354-2368.

Finch CE (1993) Neuron atrophy during aging: programmed or sporadic? Trends Neurosci 16:104-110.

Flood DG, Coleman PD (1988) Neuron numbers and sizes in aging brain: comparisons of human, monkey, and rodent data. Neurobiol Aging 9:453-463.

Flood DG, Coleman PD (1990) Hippocampal plasticity in normal aging and decreased plasticity in Alzheimer's disease. Prog Brain Res 83:435-443.

Gage FH, Kelly PA, Bjorklund A (1984) Regional changes in brain glucose metabolism reflect cognitive impairments in aged rats. J Neurosci 4:2856-2865.
Gage FH, Coates PW, Palmer TD, Kuhn HG, Fisher LJ, Suhonen JO, Peterson DA, Suhr ST, Ray J (1995) Survival and differentiation of adult neuronal progenitor cells transplanted to the adult brain. Proc Natl Acad Sci USA 92:11879-11883.

Gould E, Cameron HA, Daniels DC, Woolley CS, McEwen BS (1992) Adrenal hormones suppress cell division in the adult rat dentate gyrus. J Neurosci 12:3642-3650.

Gould E, Cameron HA, McEwen BS (1994) Blockade of NMDA receptors increases cell death and birth in the developing rat dentate gyrus. J Comp Neurol 340:551-565.

Gueneau G, Privat A, Drouet J, Court L (1982) Subgranular zone of the dentate gyrus of young rabbits as a secondary matrix: a high-resolution autoradiographic study. Dev Neurosci 5:345-358.

Kaplan MS, Bell DH (1984) Mitotic neuroblasts in the 9-day-old and 11-month-old rodent hippocampus. J Neurosci 4:1429-1441.

Kaplan MS, Hinds JW (1977) Neurogenesis in the adult rat: electron microscopic analysis of light radioautographs. Science 197:1092-1094.

Landfield PW, Braun LD, Pitler TA, Lindsey JD, Lynch G (1981) Hippocampal aging in rats: a morphometric study of multiple variables in semithin sections. Neurobiol Aging 2:265-275.

Levison SW, Chuang C, Abramson BJ, Goldman JE (1993) The migrational patterns and developmental fates of glial precursors in the rat subventricular zone are temporally regulated. Development 119:611-622.

Lois C, Alvarez-Buylla A (1993) Proliferating subventricular zonc cells in the adult mammalian forebrain can differentiate into neurons and glia. Proc Natl Acald Sci USA 90:2074-2077.

McWilliams JR, Lynch G (1984) Synaptic density and axonal sprouting in rat hippocampus: stability in adulthood and decline in late adulthood. Brain Res 294:152-156.

Mullen RJ, Buck CR, Smith AM (1992) NeuN, a neuronal specific nuclear protein in vertebrates. Development 116:201-211.

Okano HJ, Pfaff DW, Gibbs RB (1993) RB and Cdc2 expression in brain: correlations with $\left[{ }^{3} \mathrm{H}\right]$ thymidine incorporation and neurogenesis. J Neurosci 13:2930-2938.

Ono K, Tomasiewicz H, Magnuson T, Rutishauser U (1994) N-CAM mutation inhibits tangential neuronal migration and is phenocopied by enzymatic removal of polysialic acid. Neuron 13:595-609.

Palmer TD, Ray J, Gage FH (1995) FGF-2-responsive neuronal progenitors reside in proliferative and quiescent regions of the adult rodent brain. Mol Cell Neurosci 6:474-486.

Ray J, Peterson DA, Schinstine M, Gage FH (1993) Proliferation, differentiation, and long-term culture of primary hippocampal neurons. Proc Natl Acad Sci USA 90:3602-3606.

Regan CM, Fox GB (1995) Polysialylation as a regulator of neural plasticity in rodent learning and aging. Neurochem Res 20:593-598.

Rousselot P, Lois C, Alvarez-Buylla A (1994) Embryonic (PSA) N-CAM reveals chains of migrating neuroblasts between the lateral ventricle and the olfactory bulb of adult mice. J Comp Neurol 351:51-61.

Seki T, Arai Y (1993) Highly polysialylated neural cell adhesion molecule (NCAM-H) is expressed by newly generated granule cells in the dentate gyrus of the adult rat. J Neurosci 13:2351-2358.

Serra M, Ghiani CA, Foddi MC, Motzo C, Biggio G (1994) NMDA receptor function is enhanced in the hippocampus of aged rats. Neurochem Res 19:483-487.

Sloviter RS (1989) Calcium-binding protein (calbindin- $\mathrm{D}_{2 \times \mathrm{k}}$ ) and parvalbumin immunocytochemistry: localization in the rat hippocampus with specific reference to the selective vulnerability of hippocampal neurons to seizure activity. J Comp Neurol 280:183-196.

Stanfield BB, Trice JE (1988) Evidence that granule cells generated in the dentate gyrus of adult rats extend axonal projections. Exp Brain Res 72:399-406.

West MJ, Coleman PD, Flood DG, Troncoso JC (1994) Differences in the pattern of hippocampal neuronal loss in normal ageing and Alzheimer's disease. Lancet 344:769-772. 